\title{
The Establishment of a Life-cycle Carbon Emission Factor Database for Buildings in China
}

\author{
Dezhi Li ${ }^{1}$, Peng Cui ${ }^{1}$, Xin Sui ${ }^{2}$, Ping Chen ${ }^{2}$ \\ ${ }^{1}$ School of Civil Engineering, Southeast University, Nanjing 210096, China \\ ${ }^{2}$ School of Automation, Southeast University, Nanjing 210096, China
}

\begin{abstract}
To establish a life-cycle carbon emission factor database for buildings and further to measure the amount of life-cycle carbon emissions of a building accurately, this paper collects life-cycle carbon emission factors for buildings, including energy, building materials, transportation and machinery ones, on the basis of defining the concept of the carbon emission factor and the boundary. Then, Microsoft SQL Server 2005 database platform and Microsoft Foundation Classes (MFC) are applied to build "A life-cycle carbon emission factor database for buildings" in China. Users can easily browse, add, modify and delete various types of carbon emission factors. At last, the life-cycle carbon emission of a residential building in Nanjing city of Chinais calculated with the established database.
\end{abstract}

Keywords-carbon emission factor; life-cycle; building; database; China.

\section{INTRODUCTION}

The global warming is getting worse with larger and larger emissions of greenhouse gases, especially carbon dioxide. The construction industry constituted $40 \%$ in global energy use, while contributed $36 \%$ share of the emissions of carbon dioxide [1]. Therefore, to measure and develop appropriate control measures according to the carbon emissions associated with construction activities are particularly important. The most popular methods for calculating the life-cycle carbon emissions of buildings is the carbon emission factor method[2]. This method can provide comprehensive and accurate results, but relies on rational calculation and complete carbon emission factor database. Now, there are some environmental impactrelated database including Standard Reference Data (SRD)developed by the U.S. National Institute of Standards and Technology (NIST) [3], Inventory of Carbon and Energy (ICE) developed by Mechanical Engineering, University of Bath, UK research team [4] and the Athena Life-cycle inventory database developed by Athena Institute and the University of Minnesota [5]. But, main purposes of above databases are to evaluateenergy efficiency, built environment, green building rating and other aspects rather than the carbon emissions of construction alone. Chinese Life-cycle Database (CLCD) is the only open environmental impact-related database in China [6], but manydata in CLCD come from early literatures and statistical surveys, resultingin a poor timeliness. Learning from successful experiences of developed countries, this article aims to establish a lifecycle carbon emission factor database for buildings in China.

\section{DATA SOURCE}

A. The concept of measurement boundary and carbon emission factors

To calculate the building life-cycle carbon dioxide emissions, Measurement boundaryshould be defined. Considering the spatial extent, the life-cycle carbon emission factors for building must be based on the system boundaries of the building. Referring to Cui Peng et al (2013),this article sets the top plane, bottom plane and The outer contour vertical plane of buildings as the system boundary of building life-cycle carbon emission factor [7].

Considering time extent, the process boundary should be defined in the process of carbon emissions within the building life-cycle caused by energy and resource depletion. It includes five stages: materials production, materials transportation, construction, operation and maintenance, demolition and materials recycling.

This article defines "building life-cycle carbon emission factor" as: in determined boundaries, the factors that ledto director indirect carbon dioxide emissions during the building life cycle. The factors can be determined by various construction activities within the process boundary.

In this paper, carbon emissions factors are divided into four classes: energy carbon emission factor, building materials carbon emission factor, transport carbon emission factor and mechanical equipment carbon emission factor.

\section{B. Energy carbon emission factor}

(1) Fossil energy carbon emission factor

CO2 will be released from the burning of fossil energy including various types of carbon compounds such as petroleum, natural gas, coal, etc. This CO2 emission primarily depends on the chemical composition and the degree of combustion. Therefore, in the case of known carbon content of energy and carbon oxidation rate, CO2 emissions can be accurately calculated. So fossil energy carbon emission factor $=$ average calorific [9] * Carbon emission factor [8]* carbon oxidation rate [10]* $44 / 12+$ carbon emission production factor [8]. 


\section{(2) Electricity carbon emission factor}

As the world's most widely used secondary energy, electricity carbon emissions are closely related with energy structure types in all countries and regions. In different types of power generation, CO2 emission mainly comes from Thermal power. Therefore this paper chose the operating margin emission factor (OM) method given by National Development and Reform Commission on Climate Division to get the electrical energy carbon emission factor [12].

\section{Building materials carbon emission factor}

In this paper, It concludes 46 kinds of major building materials' carbon emission through consulting nearly 10 years' the National Statistical Yearbook, standards, relevant literatures and different provinces quota.

Cement, for example, released a large number of $\mathrm{CO} 2$ in its producing process. As the $89 \%$ of domestic cement production using NSP method, Zhan Jian'an et al (2013), based on this method, modified the result according to $\mathrm{CaO}$ ratio derived from non-carbonate sources of raw compound and then obtained accurate clinker and cement $\mathrm{CO} 2$ emissions data [13].

\section{Transportation carbon emission factor}

Transportation carbon emissions from railway transport, sea transport and road transport are very different. They need to be calculated separately.

\section{(1) Railway transport}

China's railway transport now mainly composed of diesel and electric locomotives. In 2012 the proportion of electric and diesel locomotives is of 53.5\%: 46.5\% [14]. In the case of a known fuel consumption per ton-km for diesel locomotives and electric consumption per ton-km for electric locomotives, rail transport carbon emission factors can be calculated $=$ Unit turnover fuel * Density of diesel ${ }^{*}$ Carbon emission factor of diesel*46.5\%+ Unit turnover electricity* electricity carbon emission factors*53.5\%.

\section{(2) Road transport}

Road transport energy consumption relates to the freight cars laden way, energy structure and loading rate etc. Combined with Turnover Fuel Consumption of petrol and diesel truck given by China's road transport energy consumption level standard [32], it can be drawn: road transport emissions factor $=$ Unit turnover fuel $*$ Density of gasoline (or diesel) *Carbon emission factor of gasoline (or diesel).

\section{(3) Water transport}

Waterway transport includes sea transport and inland transport, both of them consumes diesel fuel [15]. Similar to road transport, waterway transport carbon emission factor = Unit turnover * diesel fuel density * Diesel emissions factor.

\section{E. Mechanical equipment carbon emission factor}

\section{(1) Construction machinery}

Carbon emission factor of mechanical equipment can be converted from energy carbon emission factor which comes from the product of the respective sets of classes and each class fuel use. Construction machinery and equipment carbon emission factor $=$ Amount of sets of classes $*$ Units set of classes fuel (or electricity) [16]* Fuel consumption (or power) of carbon emission factors.

\section{(2) Daily use of equipment}

Daily use equipment mainly refers to the air condition system, lighting and gas equipment. Air condition system and lighting facilities' carbon emissions are measured by annual electricity consumption and gas equipment carbon emission is measured by annual gas consumption.

\section{THE BUILDING LIFE-CYCLE CARBON EMISSION FACTOR DATABASE}

\section{A. System overview and requirements analysis}

$<$ Building life-cycle carbon emission factor database $>$ is based on Microsoft SQL Server 2005 database platform, using Microsoft Visual Studio 2010 software MFC (Microsoft Foundation Classes) for user interface, aiming to organize, store and manage carbon emission factors. $<$ Building life-cycle carbon emission factor database $>$ has the advantage of simple operation, convenient entry, practicability. Users can easily check the form of various types of carbon emission factors and modify, add and delete. While they can also calculate the carbon emission of whole life-cycle or a certain stage by the list of project amount, a list of equipment and machinery usage, other basic information and the embedded formulas.

\section{B. Database design}

This article includes building factor database tables, traffic factor tables, mechanical factor tables, energy factor table. These four tables are independent in the query and data maintenance function. The relationships between the structures of the module in the calculation are relatively simple.

As to Database connectivity in this paper, we use "Microsoft OLE DB Provider for SQL Server" Data to link Properties and use the "connection string" to connect the database [17]. But ADO Data control itself is not able to display data in the database, so this paper, based on the data source from ADO, displays the results with the help of Data Grid (which is not available in MFC and needed to be set).

\section{User interface design}

In this paper, the design of the user interface of the system is based on the dialog box. For security, users who want to use this system must enter the correct username and password, otherwise it is unable to enter into $<$ Building lifecycle carbon emission factor database>.

Query is one of the most important functions of the database. When querying in the database with large amounts of information by using SQL statements, data table will conduct a detailed statement judge. Then all the statements which meet the conditions will be organized together to form another visual "table structure "(record set) and make up the query results without being stored.

For the convenience of users, the Life-cycle Carbon Emission Factor Inventory of Building provides the 
function of "fuzzy query keywords". The user can identify the carbon emissions of certain factors just according to the keywords contained in the factor name or the factor's serial number.

In addition, the data information in the database system can be changed at user's will. The users can add, modify, and delete the information content according to different conditions.

Meanwhile since Artificial calculation is tedious and error-prone, <Building life-cycle carbon emission factor database $>$ easily solves this problem. According to the characteristics at various stages in the life-cycle, the calculation interface is designed as the Tab label type dialog. Each of the tags defines different classes and better reflects the code readability and object-oriented encapsulation. Each tag respectively represents the four stages and the calculation results: building materials production and transportation, building construction, operation and maintenance, dismantling and recycling. Through ADO Data control and Data Grid control, all kinds of carbon emission factor tables in the database are connected to the interface and combined with the embedded calculation formula. Then its operational function is achieved.

\section{CASE STUDY}

To display the life-cycle total carbon emissions, the unit carbon emissions and its proportion in different stages in the interface of the calculation results. This article takes an affordable housing for workers in Zhu Town, Liu He District in Nanjing as a case to calculate the life-cycle carbon emissions of the brick- structure residential building of four floors (a total construction area of $1838.78 \mathrm{~m}^{2}$ ) in each stage and the proportion. The result is shown in figure 1.

It can be seen from the results that the amount of carbon emissions in the building's operation phase is the largest $(66.67 \%)$ while the mitigation measures in this phase should focus on taking the high efficient, energy-saving water and electricity equipment and strengthening the consciousness of saving water and electricity in daily life; Carbon emissions of materials' production is in the second place, about 32.64\%. Therefore builders should be advocated to use more environmental-protection building materials and improve the level of building materials production technology from the source; Carbon emissions in transport phase accounted for only $0.62 \%$, the reason is that the selected building materials factories are very near projects so that a large amount of transportation of oil and electricity consumption is saved; Carbon emissions in construction phase account for $1.07 \%$, which mainly come from mechanical equipment energy consumption. It should be proposed to make more reasonable construction scheme in order to reduce the use of machinery and equipment, and more use of clean energy; Building demolition and construction materials recycling stages appeared negative carbon emissions. So if it can be further improved that the waste materials recycling and recovery process, this phase will have a larger carbon reduction space.

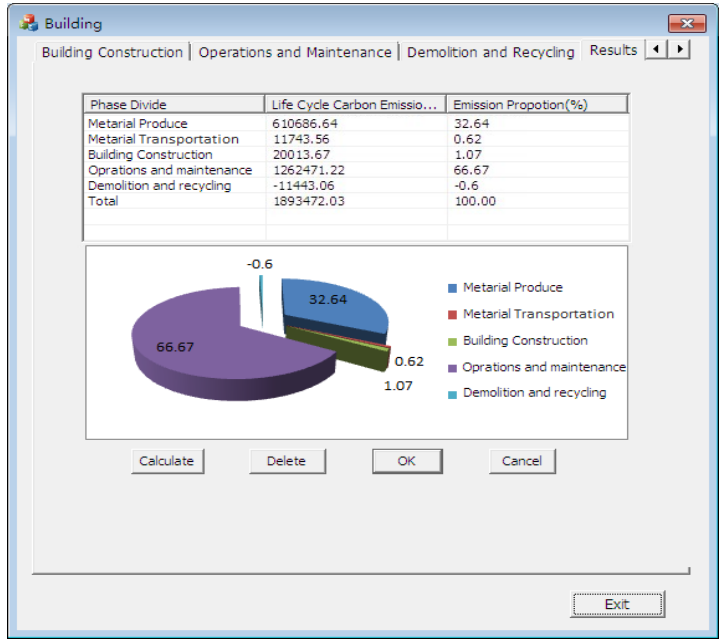

Figure 1. Results Schematic Diagram

\section{V.CONCLUSION AND PROSPECT}

The life-cycle carbon emission of Buildings is an important part of social carbon emissions. Its measurement is the foundation of construction energy conservation and emissions reduction, carbon trading in construction field and development of low carbon buildings. It is also one of the research highlights in the field of sustainable development at home and abroad. This paper gathered lifecycle factors inventory of buildings including energy carbon emission factor, building materials carbon emissions factors, transportation emissions factors and mechanical equipment carbon emissions factors, and built the life-cycle carbon emissions factors inventory system of buildings, which can query and calculate the life-cycle carbon factor of buildings.

Learning from foreign experience and summarizing lifecycle carbon emissions measurement research of buildings in our country, it can be found that foreign related database focuses on comprehensive evaluation like energy efficiency in buildings and the green building grade. The measure of construction carbon emissions is in the lack of specialized study. Life-cycle carbon emissions research of buildings in our country has got some achievements, but the data lack of timeliness. Suggestions for the future direction of the research include:

(1) Further combine life-cycle carbon emission factors inventory system with related project cost software and quantity calculation software. Put CAD quantity into the software in order to realize the automatic calculation.

(2) Strengthen research collaboration between national, intergovernmental organizations, and scholars. Unify carbon emissions measurement phase and calculate boundary to avoid repeating calculation or omission.

(3) Apply the idea of sustainable and recyclable to every aspect in the life-cycle of a building. Fully consider direct and indirect carbon emissions. Expand the boundaries of the system to the surrounding green belt and even the whole community and take into consideration of the effect of carbon sink in future. 
(4) Use the successful experience of United States, Britain, Japan and other developed countries for reference. Establish and improve our country's carbon emissions factor database by encouraging enterprises to measure and label the carbon emissions.

(5) Combine BIM, GIS and other emerging technologies. Measure the life-cycle carbon emissions of buildings in different stages. Establish intelligent measuring integration platform for carbon emissions.

\section{ACKNOWLEDGEMENTS}

The research work was supported by National Natural ScienceFoundation of China under (Grant No. 71301024)and the Priority Academic Program Development of Jiangsu Higher Education Institutions (PAPD) and Southeast University (gs3) (Grant No. XJ2008309).In addition, I would extend my thanks to Guo Kai for all his kindness and help for the translation.

\section{REFERENCES}

[1] Ping Yu, Xiaoqiu Chen, Luyi Ma. Review of life-cycle carbon emissions research of Residential building [J]. Building Science. 2011(04): 9-12.

[2] Tao Zhang, Jiajie Wu, Yun Le. The calculation method of the whole life-cycle period of $\mathrm{CO} 2$ emissions of building materials [J].Journal of Engineering Management. 2012(01): 23-26.

[3] National Institute of Standards and Technology. Free Standard Reference Databases [DB/OL]. http://www.nist.gov/srd/onlinelist.cfm, June 17, 2010.

[4] Hammond, G. \& Jones, C. Inventory of carbon and energy (ICE): version 1.6a. Sustainable Energy Research Team, University of Bath, UK, 2008.
[5] Athena Sustainable Materials Institute LCI/LCA Product Reports[EB/OL]. http://www.athenasmi.org/resources/publications/, 2014

[6] Yike Environment Technology Limited Company. Database comparison table of each edition [EB/OL]. http://www.itke.com.cn/index.php?_m=mod_article\&_a=article_cont ent\&article_id=116, 2012-01-04.

[7] Peng Cui, etc.Life-cycle ecological efficiency measurement method research of Residential construction [J].Building economic. 2013(11): 96-99.

[8] Intergovernmental Panel on Climate Change. 2006 IPCC guidelines for national greenhouse gas inventories. In: Energy, Vol. 2; 2006, http://www.ipcc-nggip.iges.or.jp/public/2006gl/vol2.html; 2006.

[9] China institute of standardization and information classification and coding etc. The general principles of the comprehensive energy consumption calculation (GB/T2589) [S]. Beijing, 2008.

[10] Aling Zhang, Wei Shen.The life-cycle analysis of automotive alternative fuel [M]. Beijing: Tsinghua university press, 2008.

[11] Yongping Yang, Zhiping Yang, Gang $\mathrm{Xu}$, etc.The situation and outlook of energy consumption of thermal power [J].Proceedings of the csee2013(23): 1-11.

[12] 2013 China regional emission factor of power grid baseline [S]. Beijing, The national development and reform commission department of climate, 2013.

[13] Jianan Zhao, Danqing Wei. Typical research of carbon emission coefficient estimates of cement production in China [J]. Science of Resource. 2013(04): 800-807.

[14] Yearbook editorial office of the People's Republic of China. The yearbook of the People's Republic of China [S].Beijing, 2013.

[15] Yearbook editorial office of the People's Republic of China. The yearbook of the People's Republic of China [S].Beijing, 2010.

[16] Construction department of shandong province. Construction machinery unit price table of construction project in Shandong [S].Jinan, 2008.

[17] Qiming Studio. Database application system development and instances of visual C++ +SQL Server [M].Posts and Telecom Press, 2004 